\title{
Hospitalidade: uma reflexão no curso do processo civilizador
}

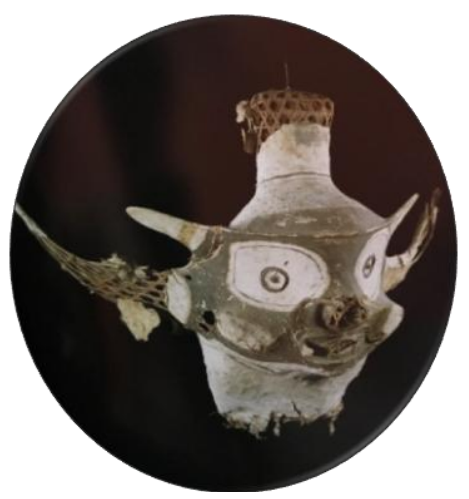

\author{
Tathiana de Alcantara Macedo Daou1 \\ Glaucio Campos Gomes de Matos2 \\ Evandro de Morais Ramos3
}

\begin{abstract}
Resumo
O processo civilizador acompanha as sociedades ao longo do seu desenvolvimento e apresenta modificações nos padrões de conduta. Regras de etiqueta e de bons relacionamentos são marcas desse processo. A hospitalidade está inserida nesse processo e oscila para mais ou para menos, influenciada pela individualização e pela diferenciação social ocorrendo nas sociedades mais complexas. Tecer uma reflexão da hospitalidade no contexto de comunidades mais simples sob a ótica do processo civilizador constitui o objetivo deste artigo. A abordagem é qualitativa e a pesquisa é bibliográfica com aporte de Alain Montandon, Luiz Octávio de Lima Camargo na perspectiva do processo civilizador de Norbert Elias, auxiliado pelas discussões de Gláucio Matos (2015).
\end{abstract}

Palavras-chave: Processo civilizador. Cortesia. Hospitalidade.

\begin{abstract}
The civilizing process accompanies societies throughout their development and changes in patterns of conduct. Rules of etiquette and good relationships are hallmarks of this process. Hospitality is embedded in this process and oscillates more or less, influenced by individualization and social differentiation occurring in more complex societies. The purpose of this article is to offer a reflection of hospitality in the context of simpler communities from the point of view of the civilizing process. The approach is qualitative and the research is bibliographical with the contribution of Alain Montandon, Luiz Octávio de Lima Camargo in the perspective of the civilizing process of Norbert Elias, aided by the discussions of Gláucio Matos (2015).
\end{abstract}

Keywords: Civilization. Courtesy. Hospitality.

${ }^{1}$ Mestranda do Programa Pós-Graduação Sociedade e Cultura na Amazônia (PPGSCA/UFAM).

2 Professor do Programa de Pós-Graduação Sociedade e Cultura na Amazônia da Universidade Federal do Amazonas.

3 Professor do Programa de Pós-Graduação em Sociedade e Cultura na Amazônia (PPGSCA-IFCHS-UFAM) 


\section{INTRODUÇÃO}

Norbert Elias (1994) ao elaborar a teoria do processo civilizador nos apresenta discussões acerca de como a sociedade ocidental caminhou rumo ao controle dos instintos, ao autocontrole, o controle das emoções, repugnância à violênia, limiar de vergonha entre outras qualidades vistas em homens e mulheres ocidentais. Mostra como os modos, os comportamentos mudaram ao longo do processo do desenvollvimento da sociedade. Mostra ainda, em seu trabalho empírico, as diferenças entre as classes sociais da época, mais especificamente de Corte, o refinamento nos modos, regras de etiquetas, boas maneiras à mesa são marcas dessa civilização.

Diante do que vemos, daquilo que a sociedade ocidental desenvolveu, por vezes de forma dolorosa, destacamos como objeto deste artigo, a hospitalidade como um marco do processo civilizador que avança pelos rios e florestas, penetrando nos lares dos amazônidas, sejam, indígenas ou não indígenas, porém, oscilando para mais ou para menos, influenciada pela individualização e diferenciação social.

A hospitalidade dentre muitos significados, pode ser caracterizada em sua relação ao bem receber entre diferentes grupos humanos, representando uma categoria de análise no curso desse processo. Nas reflexões de Matos (2015), o processo civilizador não saiu da floresta, mas penetrou nela sem pedir licença. Portanto, entendemos que a hospitalidade é uma distinção social no curso desse processo.

A medida que o processo avança, os padrões de cordialidade e boas maneiras se elevam, estabelecendo novos níveis para o que é considerado civilizado. O bem receber próprio de cada cultura é impregnado de todos esses padrões, sendo, no entanto, a hospitalidade uma característica associada historicamente à virtude, humildade, divindade. 


\section{Processo Civilizador}

A civilização descrita por Norbert Elias (2011) é um processo ao qual todas as sociedades estão sujeitas e em que todos os indivíduos estão inseridos, sem que haja um protagonismo individual, ou seja, o processo ocorre de forma autônoma, dado os objetivos e metas próprias de cada integrante. Há diferentes níveis de civilização onde não necessariamente implicam em tempos cronológicos distintos: podem existir povos em diferentes estágios do processo civilizador numa mesma época. Não há como determinar quando chegará ao ápice, nem mensurar o grau de civilidade, pode-se saber, no entanto, a direção do processo que ainda está em curso.

Em seu livro O Processo Civilizador, Elias (2011) reflete sobre o que aconteceria se um homem da então sociedade atual fosse deslocado no tempo para uma época anterior aquela: ele teria a sensação de que estava num grupo menos civilizado que o dele. Assim, sugere ainda que a análise em retrospecto é mais simples de se fazer já que há a possibilidade de se avaliar o contexto e comparar com o quadro atual.

Os fatores para observação desse processo atrelam-se diretamente ao nível de autoconsciência, mas é interessante salientar que Elias (1994) discorre amplamente em seu livro A sociedade dos indivíduos que a individualização está proporcionalmente ligada ao coletivo, portanto o nível de autoconsciência está relacionado ao nível de civilização, caminhando de forma contígua o prisma individual e o coletivo. Ainda que um indivíduo se afaste de sua sociedade, fará gestos pensando no seu coletivo. Nas palavras de Elias (1994) “o indivíduo sempre existe, no nível mais fundamental, na relação com os outros, e essa relação tem uma estrutura particular que é específica de sua sociedade. (p. 31)

Nesse contexto, a tríade dos controles básicos, proposto por Norbert Elias, é apresentada: controle da natureza, autocontrole e relações 
interpessoais, oferecendo um viés para analisar o desenvolvimento de sociedades. Gláucio Matos (2015) em sua obra "Ethos e Figurações na hinterlândia amazônica" analisa três comunidades amazônicas sob a perspectiva do processo civilizador de Norbert Elias e o seu seguidor Johan Goudsblom, o qual destaca três níveis para falar desse processo: o individual (necessidade do indivíduo de aprender), sociocultural (padronização da criança conforme condutas aceitas na sociedade) e história humana mais ampla (não existe grupo humano a viver sem normas). (p. 37 a 43)

A individualização é parte do desenvolvimento da sociedade, que no decorrer do processo tornam seus integrantes individualistas e atomizados, mas que querendo ou não vivem, segundo Elias (1994b) em relação de interdependência funcional, ou seja, os seres humanos organizam-se em grupos formando diferentes figurações e formando teias de interdependência das mais diversas naturezas e formas. Matos (2015) nos fornece inúmeros exemplos dessas teias em comunidades amazônicas, como por exemplo numa prática como a pesca. Um peixe vendido em uma feira da capital amazonense pode simbolizar uma imensa teia de interdependência que vai desde o pescador, passando por um atravessador e chegando ao vendedor, envolvendo ainda o indivíduo que vai comprar esse peixe. Caso esse pescado esteja num período que não possa ser comercializado devido a Lei do Defeso, por exemplo, essa rede se amplia envolvendo os fiscais pertencentes aos órgãos reguladores e toda a rede que alimenta essa conduta considerada ilícita.

Retomando as noções de autoconsciência e da tríade de controles básicos, descrevemos o exemplo acima: no processo civilizador o homem buscou controlar a natureza, assim o homem observou a natureza para saber quando e como pescar determinada espécie de peixe e desenvolveu mecanismos e utensílios para isso; desenvolveu um maior controle sobre si já que precisou adaptar-se as condições externas para pescar o peixe e 
controlar características fisiológicas e psicológicas; e por último precisou estabelecer uma relação com outras pessoas para desenvolver uma teia inicial para a ocorrência da atividade, por mais que num outro estágio a teia se amplie sem que o indivíduo tenha noção ou controle sobre isso, são as redes invisíveis.

As redes invisíveis implicam em concluir que o indivíduo pode se visualizar como autor, isto é, “eu”, de determinados processos, mas pode não se sentir parte do "nós" quando visualiza uma rede mais ampla de interdependência. Quanto mais o indivíduo consegue se distanciar de si e analisar a rede ao qual faz parte de maneira externa, maior o nível de autoconsciência.

Assim, as figurações são ligações humanas, essas teias de interdependências funcionais nas quais homens e mulheres se inserem e não menos se estão sob relações de poder. A medida que essas relações se tornam mais complexas, há necessidade de um olhar mais apurado para buscar, captar, no seio dessas figurações, seus objetivos.

Os mecanismos de controle, a ação ou presença do Estado, coações externas, que se tornam autocoações, a questão do tempo como uma construção simbólica, são por assim dizer, elementos que desencadearam boas maneiras, bons modos, estudados por Norbert Elias. Uma criança nasce sem nenhuma noção de comportamento, mas com o potencial biológico para aprender. O padrão social aceitável é imposto por seus pais, que o receberam por sua vez de seus avós e assim sucessivamente. O ser humano é "obrigado" a civilizar-se para ser aceito na sociedade.

O conceito de sociedade de Elias (1994) corrobora e conclui o encadeamento de ideias desenvolvido acima:

Em virtude dessa inerradicável interdependência das funções individuais, os atos de muitos indivíduos distintos, especialmente numa sociedade tão complexa quanto a nossa, precisam vincular-se ininterruptamente, formando longas 
cadeias de atos, para que as ações de cada indivíduo cumpram suas finalidades. Assim, cada pessoa singular está realmente presa; está presa por viver em permanente dependência funcional de outras; ela é um elo nas cadeias que ligam outras pessoas, assim como todas as demais, direta ou indiretamente, são elos nas cadeias que a prendem. Essas cadeias não são visíveis e tangíveis, como grilhões de ferro. São mais elásticas, mais variáveis, mas mutáveis, porém são menos reais, e decerto não menos fortes. E é a essa rede de funções que as pessoas desempenham umas em relação a outras, a ela e nada mais, que chamamos "sociedade". (p. 23)

Segundo Elias (1994a) a civilização não é boa e nem má, é o que registra um sociólogo. Ao deslocarmos para a colonização do Brasil, em uma análise pretérita, vemos o encontro dos civilizados com os amerídios que aqui residiam. Nesse encontro, muitos grupos étnicos foram exterminados, espoliados, suas línguas extintas, escravizados, o que Matos (2015), se refere como surto descivilizatório sobre o grupos étnicos existentes. Por força da persuasão, relações de poder, o processo civilizador ocidental foi incrementado, no entanto, na relação com a natureza, os ameríndios eram mais civilizados que os colonizadores. Nas palavras de Matos (2015), “diante do ambiente, os indígenas possuíam um nível civilizacional superior aos homens e mulheres "polidos e polidas" que aqui chegaram”. (p. 44)

A sensibilidade frente a natureza era e faz parte da civilização indígena independente do desenvolvimento civilizacional que foi imposto ligado a padrões europeus de comportamento, sentimentos, regras de boas maneiras, costumes, relações de poder. Matos concorda com Elias e ressalta que:

... sou levado a pensar com Norbert Elias (1994), que nesse longo processo de contato de integração, grupos étnicos, isto é, o coletivo, não escapou de mudanças/evoluções da sensibilidade e nas relações sociais - sociogêneses. Da mesma forma o indivíduo não escapou de mudanças de comportamento e na estrutura de sua personalidade psicogênese. (p. 61) 
No curso desse processo descrito, analisando em retrospectiva a história de uma Amazônia colonizada, onde as interações foram moldadas em virtude de um modelo externo, como as relações mais simples se manifestam? Simples no sentido de mais fundamental: a primeira interação entre um indivíduo e outro. Esse contato, fruto de um encontro pode mexer com regras sociais de bons relacionamentos, dentre elas a hospitalidade como forma de acolhimento. No percurso do processo civilizador onde as interações humanas transformam e moldam, como a hospitalidade altera-se e o que ela representa?

\section{Hospitalidade}

A hospitalidade pode direcionar-se para um conceito relacionado ao encontro, sentimentos e trocas, de acolhimento, de receber, porém está longe de ser uma definição que encerra todo seu significado. $O$ encontro entre pessoas implica em hospitalidade, porém compreende seu extremo oposto exatamente no mesmo ato: a hostilidade. Encontrar alguém pode ser algo positivo, porém engloba todo o contexto hostil que o outro traz. No entanto, conforme já vimos na concepção de figuração, o ser humano vive numa relação de interdependência, ele precisa do outro, se reconhece na relação com o outro, e a hospitalidade pode ser um diferencial humano, sem que faça juízo de valor de outro humano.

Ser hospitaleiro porém, à luz da teoria eliasiana, é bem mais complexo do que parece, a medida que uma sociedade torna-se civilizada, mais cordial deveria ser. Porém essa cordialidade representa algo ensaiado, imposto, aprendido com os mais velhos como sinal de boas maneiras, de qualidades humanas, sendo por outro lado a hospitalidade algo supostamente ligada a um bem-receber natural, próprio do indivíduo, o que segundo a teoria não seria possível, já que não existe uma atitude natural no homem, e sim um adestramento e um condicionamento. 
Alain Montandon em "O livro da Hospitalidade" salienta que "a hospitalidade é sinal de civilização e humanidade" (p. 31), após citar Ulisses na Odisseia (XIII, vv.200-202) "vou encontrar brutos, selvagens sem justiça, ou homens hospitaleiros, tementes aos deuses?” Há quase uma inversão bem difícil de ser compreendida: a hospitalidade é algo natural e individual ou característica profunda de um grau de civilização? $\mathrm{O}$ mesmo autor (2011) referencia Norbert Elias em outro momento:

\begin{abstract}
As regras de cortesia estão mais do que nunca em vigor na cena hospitaleira que encerra muitos perigos. Uma vez tendo entrado, a modéstia, a reserva, a negação da intrusão e a aparência de submissão devem ser claramente percebidas. O território do outro é sempre objeto de uma sensibilidade escrupulosa. A comunidade joga incessantemente com a presença e a distância, com uma presença como favor e uma distância como benevolência. Entrar no círculo é renunciar a se impor, dar prova de submissão e de obediência à sociedade. Essa renúncia à autoridade sob todas as suas formas faz parte desse processo de civilização descrito por Norbert Elias e de uma educação social cujas consequências psicossociológicas e políticas são capitais. (p. 32)
\end{abstract}

E nesse ambiente marcado por ambiguidades, surge o cenário da hospitalidade repleto da hostilidade, sendo ao mesmo tempo traço individual e coletivo, divino e humano, civilizado e natural. Sobre o natural como contraditório do civilizado, Renato Janine Ribeiro ( 2011) em sua apresentação a Norbert Elias no livro O Processo civilizador manifesta-se "Afinal, atualmente se privilegia mais a franqueza, mais o desnudamento que o recato extremo, não apenas no plano físico como também no psíquico" (p. 10). Concluindo que esse desnudamento constitui o contrário do ápice da civilização previsto por Elias. A hospitalidade atual seria resultado desse desnudamento ou característica de civilização ou é, no curso do processo civilizador, que a hospitalidade sofre interferência?

Para Elias (2011), as boas maneiras estão presentes no decorrer do processo civilizador. Ele discorre amplamente sobre o conceito de cortesia ligado de certa forma a hospitalidade. O conceito de cortesia, no entanto, 
estava atrelado inicialmente à Corte e passou por alterações envolvendo seu significado semelhante ao que aconteceu depois com o termo "civilização" até que atingisse a definição atual. Assim, a cortesia é sinônimo de civilização e ao longo da história a hospitalidade verdadeira era exercida por pessoas mais pobres e portanto, menos civilizadas. (p. 36). Seriam então conceitos contraditórios ou complementares?

Elias (2011) expõe sobre a roupagem que o termo "cortesia" assumiu posteriormente, mostrando que ser "cortês" segundo os padrões civilizados implica em observar em volta e prestar a atenção às pessoas (p.86). Ou seja, um padrão imposto, moralmente aceitável, em outras palavras, civilizado. Ser hospitaleiro por sua vez, também implica em observar certas normas estabelecidas, por mais a vontade que o anfitrião ou hóspede sintam-se, existe o medo e a hostilidade que o fazem observar e respeitar as regras de convivência. Sendo assim, o indivíduio cortês pode ser hospitaleiro e vice-versa.

Ao longo do curos do desenvolvimento das sociedades, a hospitalidade tornou-se inerente às ações de bem receber o outro. Ser civilizado culmina em assumir determinada função. Para Elias (1994), "Não lhe é possível, simplesmente, passar para outra função, mesmo que o deseje." (p. 21) E em seguida: "cada qual é obrigado a usar certo tipo de traje; está preso a certo ritual no trato com os outros e a formas específicas de comportamento..." Ser hospitaleiro significa usar de forma mais rígida as máscaras ou despir-se delas?

Trazendo a discussão para hoje, até que ponto se mantem uma sociedade hospitaleira ou uma hospitalidade civilizada quando o domínio do capital dita regras de atendimento corporativo e isso se incorpora ao cotidiano dos indivíduos? Analisando sob o viés do conceito figuracional, as grandes empresas exercem poder e ditam normas civilizatórias quanto ao atendimento, denominado por alguns autores, dentre eles Luiz Octávio de Lima Camargo (2011) como hospitalidade encenada. Essa questão talvez 
seja chave para entendermos um dos aspectos da hospitalidade, é quando forja o indivíduo ou grupo a ser hospitaleiro, naquele tempo e espaço, em função do econômico.

E nesse contexto permeado de paradoxos e perguntas, voltamos o olhar para a realidade amazônica e tentamos traçar um esboço de resposta. O receber em uma comunidade amazônica não se distancia muito do padrão encontrado na cidade, porém distancia-se na forma em que é estabelecido. Comunidades ao receber visitantes, por exemplo, sabem previamente, planejam-se, sabem quem é seu hóspede, ao tempo que se por um lado possuem um ar de mais hospitaleiros por terem sua simplicidade atrelada as suas características de recepção, por outro detém todo o conhecimento necessário para agradar o forasteiro, a exemplo do que ocorre em qualquer hotel citadino.

Nas cidades, a hospitalidade hoteleira continua a ocorrer de forma cada vez mais mecânica e ensaiada, o acolhimento desvinculado da hospedagem, o receber em casa vai deixando de ser algo comum e passando a uma situação restrita a amigos íntimos. O contexto agitado de uma cidade, a violência crescente dentre outros fatores não favorece a ajuda ao próximo.

A hospitalidade vai deixando de ser algo fundamental e ligada à dádiva, no sentindo de acolhimento a qualquer que seja o outro e passa a ser algo muito mais relacionado ao contexto da hospedagem turística.

No curso do processo civilizador, observamos que a individualização e a diferenciação social vêm mexendo com o que ser hospitaleiro em sua essência. Parece ser um paradoxo refletir sobre hospitalidade, pois na mesma sociedade encontramos indivíduo ou grupos uns mais, outros menos hospitaleiros. Deslocando o olhar para comunidades simples, encontradas no universo amazônico, nos surpreendemos com o nível hospitaleiro de seus membros, porém, à medida que se integram às sociedades mais complexas e o econômico passa 
a orientar alguns indivíduos, a hospitalidade aparenta se mais mecânica do que espontânea.

\section{Considerações Finais}

O curso do processo civilizador continua e com ele as sociedades estabelecem, criam e recriam normas de conduta e padrões que devem ser aceitáveis nas relações interpessoais. Cortesia, cordialidade, boas maneiras de uma forma geral são marcas resultantes do longo percurso pelo qual as sociedades ocidentais passaram. A hospitalidade, não foi diferente. Ela não ficou à margem desse processo e torna-se um diferencial social, uma distinção no contexto de uma comunidade que tem como foco, a hospedagem de outros indivíduos. No entra e sai desses indivíduos na comunidade, a exemplo de turistas, valores são incorporados, condutas são repensadas e a distinção se faz notar.

O povo brasileiro é considerado, de forma generalizada, hospitaleiro. Essa inferência generalizada carrega consigo a ideia de que qualquer que seja o habitante de nosso país abre suas portas ao visitante, também, qualquer que seja. Essa carga ideológica, traz como pano de fundo um slogan de interesse econômico, principalmente atrelado ao turismo, que diga de passagem, tem surtido efeito. Mas é no dia a dia, nos diversos estados e municípios que compõem essa nação é que damos conta, principalmente seus descendentes, de diferenças na hospitalidade.

Observamos, no curso do processo civilizador ocidental que avançou nos quatro cantos do Brasil, um maior nível de individualização e diferenciação social, que não acabou com a hospitalidade, mas ela não se abre mais a qualquer indivíduo. Vemos figurações específicas, a exemplo de condomínios fechados, que só entra quem for de confiança e autorizado, após, obviamente checar sua verdadeira idoneidade. Isso não implica dizer 
que a hospitalidade não existe nesse espaço fechado, pois entre seus pares, a hospitalidade se faz presente.

Quando observamos sociedades mais simples a exemplo de comunidades amazônicas, nos surpreendemos ao ver o nível de hospitalidade manifesta. Dessa forma, somos levados a sugerir que, com o maior nível de individualização e diferenciação social pelos quais passam uma sociedade, a hospitalidade já não é extensiva a todos.

\section{Referências}

CAMARGO, Luiz Octávio de Lima. O estudo da hospitalidade. In: O livro da hospitalidade: acolbia do estrangeiro na bistória e nas culturas. Sob a direção de Alain Montandon; tradução de Marcos Bagno e Lea Zylberlicht. São Paulo: Editora Senac, 2011.

ELIAS, Norbert. A sociedade dos indivíduos. Organizador por Michael Schröter; tradução Vera Ribeiro. Rio de Janeiro: Zahar, 1994.

ELIAS, Norbert. O processo civilizador, volume I: uma história dos costumes. Tradução Ruy Jungmann. Rio de Janeiro: Zahar, 2011.

MATOS, Gláucio Campos Gomes de. Ethos e figurações na binterlândia amazônica. Manaus, AM: Editora Valer/Fapeam, 2015.

MONTANDON, Alain. Espelhos da hospitalidade. In: O livro da hospitalidade: acolbida do estrangeiro na história e nas culturas. Sob direção de Alain Montandon; tradução de Marcos Bagno e Lea Zylberlicht. São Paulo: Editora Senac São Paulo, 2011. 